\title{
FUZZY AHP MODEL FOR \\ THE DETERMINATION OF THE LOCATION OF THE NAVAL BASE (STUDY OF THE MARITIME SECURITY AND DEFENSE SYSTEM IN INDONESIA)
}

\author{
Ahmadi \\ Departement of Industrial Engineering, \\ Naval College of Technology, Surabaya, Indonesia \\ ahmadi_raha@yahoo.com
}

\begin{abstract}
The Location determination is a strategic issue both in business and public. There are many factors leads to management decisions in expanding or relocating their business facilities. With the improvement in technology especially communication and information technology, Have made the time and space constrain insignificant for managers in doing their businesses. A few existing theory and method in determining location have tend to refer to the profit oriented issues, where more of its decision variables are able to measured precisely. The most common method used was procedure ranks method, centre of gravitation analysis method and the linear programming method. Recent development have shown that many location determination issues have been resolve by using Analytical Hierarchy Process (AHP) method. A few disadvantage of the traditional AHP method that was requirement of every factors or indicators in the same level to be independent have been anticipated by using Fuzzy sets theory approach.

The military base location determination issue is a complex issue which involve unmeasurable variables. This decision variables was ideology, politics, economy, social-cultural, defence and security. Fuzzy AHP Method was the development from the traditional AHP method that was superior to use in resolving problems of multi-variable decision makings which involve unmeasurable variables, such as military base location determination issues.
\end{abstract}

Keyword: Public Facility Location, military base, Fuzzy AHP..

\section{Introduction}

The location determination issues have had their special position in the Operation Research field since the early 1960s. It was started with issues of decision making in the location determination of factories, warehouses, schools, and hospitals to deliver an efficient service (Francis, R.L, et.al, 1992, Frank C., 2005). The issues of facilities location determination is not only faced by new companies but also by long operating companies.

Generally, there are a few research gap found in the location determination decision makings, that is:

a. Research of location determination decision making have always been dominated by business sector or public sector profit oriented issues. Research of location determination of non profit oriented public sectors is still limited, especially the military base location determination issues from the management point of view in Indonesia have not been conducted.

b. Stakeholder interest in base location determination have not been significantly accommodated.

c. There were no military base location determination model involving stakeholder interest have been found so far. 


\section{Literature Review}

\subsection{Facility Location}

The location theory have been known and developed since 1933. Until today the development of location theory have experienced a few stages, there are a few figure that have done many thing for the development of location theory, starting from K-3 theory from Chistaller, Von Thunnen theory and Weber theory which have introduce us to the industrial location determination issues. In studying various activities, economist have already made an assumption that the space analysed was flat and have the same condition in every direction (Tarigan, 2006). This assumsion is often not in accordance with the reality of the matter. The assumption is too simple and far from reality would make the results of the analysis is skewed

Analytical Hierarchy Process (AHP) Method is a functional hierarchy with the main input of perception. With the hierarchy, an unstructured complex issue broken down into groups and this groups will be arranged in a hierarchical form. AHP model approach is almost identical with the political behaviour model, that is the decision model (individual) by using collective approach from the decision making process.

\section{$2.2 \quad$ Set Concept and Fuzzy Set Theory}

a.

\section{Classic Complex Concept (Crisp)}

In the classic complex concept (crisp), the existence of an element in a set A, can only have 2 membership probability, that is becoming the member of set $\mathrm{A}$ or not becoming member of set A (Chak in Kusumadewi et al, 2006). A value showing the level of element membership (x) in a set (A), is commonly known as membership value or degree of membership, which was notated with $\mu_{A}(x)$. In the classic set there are only 2 membership value, that is $\mu_{A}(x)=1$ with $x$ becoming the member, and $\mu_{A}(x)=0$ with $x$ not becoming the member of set $A$. This makes the two elements that have very small difference that was located at the transitional area will be on two different membership as shown in Figure 1.

Fi

In these

it was

located in two c

2 a 10

point difference

were

weaknesses in tl

cases

with a considera

b.

Fuzzy set theory is a mathematical framework used to represent uncertainty, vagueness, impreciseness, incomplete information, and partial ignorance (Tettamanzi, 2001, Cheng $\mathrm{Ru} \mathrm{Wu}$ et al, 2008). Uncertainty could also be used to describe something related to uncertainty which was presented in the form of linguistic information or intuition. For example, to express a product as "good", or the importance level by a decision maker as "very important". Zadeh (1995) pointed that, usually a preposition that contains uncertainty is a fuzzy, but not vice versa. In the Multi Criteria Decision Making (MCDM) issues, uncertainty was also better presented using fuzzy concept than using probability. The probability approach 
needed probability distribution with known assumption of the parameter or the initial parameter assumed and corrected by using Bayesian approach (Pedrovic, 2002).

\section{c. Membership Function}

Membership function from a Fuzzy set is a curve that shows data input points mapping to its membership values. One of the method used to obtain membership value was by using function approach. Membership function in a fuzzy set describe the information contained in this fuzzy set (Zadeh et al., 1995). Membership function in the Triangular Fuzzy Number (TFN).

TFN ( Triangular Fuzzy Number ) mathematically is easy to implicate, and more importantly, it represent the basic rational thinking to measure vague knowledge in most decision making problems.

For example, $\mathrm{P}_{1}=(\mathrm{a}, \mathrm{b}, \mathrm{c})$ and $\mathrm{P}_{2}=(\mathrm{d}, \mathrm{e}, \mathrm{f})$

$\mathrm{P} 1+\mathrm{P} 2=(\mathrm{a}+\mathrm{d}, \mathrm{b}+\mathrm{e}, \mathrm{c}+\mathrm{f})$ additionP1 - P2 $=(\mathrm{a}-\mathrm{d}, \mathrm{b}-\mathrm{e}, \mathrm{c}-\mathrm{f})$ substractionP1 $+\mathrm{P} 2=\left(\mathrm{a} * \mathrm{~d}, \mathrm{~b} * \mathrm{e}, \mathrm{c}^{*} \mathrm{f}\right) \operatorname{dimana} \mathrm{a}=0$,

\section{d. Fuzzy Analytical Hierarchy Process}

Analytic Hierarchy Process (AHP) is an effective method to resolve problems consist of social, economic, technical and political factors which its evaluation needed a linguistic variable (Askin and Guzin, 2007). AHP application in the Multi Criteria Decision Making (MCDM) process, which often criticized, is where a decision maker is face with a complicated problems which was difficult to have a certain value in determining the weight of every criteria in the pairwise comparison matrix (Deng, 1999). Many literature have shown that there were situation where assessment was conducted by using an imprecise comparing ratio (Leung and Chao, 2000). Most of the problems in the real world, are that some of the data for decision making could be precisely predicted, where some is unable to be predicted. Human often fail in making prediction to the assessment of a problem quantitatively, however, they can efficiently value a problem qualitatively (Kulak and Kahraman, 2005).

\section{e. Linguistic Variable}

One of the important element in the fuzzy Analytical Hierarchy Process approach is the linguistic variable, that is a variable where the value is in natural or artificial language sentences (Zadeh, 1975). In the triangular fuzzy number (TFN), every membership functions (fuzzy number scale) was defined with three TFN symmetrical parameter that is the bottom value, middle value, and upper value. The use of linguistic variable was to analysed the linguistic priority given by the evaluator that contribute to the decision making. Linguistic judgement follows the conversion table modified from Saaty's priority scale.

To conduct the weighting process by using Fuzzy Analytic Hierarchy Process approach, the assessment data have to be converted to numerical data. Conversion table of the linguistic variable to the triangular fuzzy number could be conducted.

\section{Research Method}


Distinct from general research, this research conducted a case study in the defence and security system in Indonesia, therefore, this research knows no population and samples. This research used research resources from respondents of experts coming from the stakeholders of Military base in Indonesia. The type of this research was perceptional research to obtained decision variables and its indicators in the location determination strategy of the Naval Base.

The research sample collection was in Surabaya and Jakarta. Whereas the research period lasted for ten months, starting at September 2008 until June 2009. The sample collection in this research was categorized as a non-probabilistic sampling, and it used a purposive sampling method because the information needed in this research could only be obtained from people with certain criteria (Uma Sekaran, 1992). The method used in this research required the respondent to be experts/specialist, therefore, only people in certain position that were most appropriate to deliver the needed information. This is the reason why the design judgement sampling was chosen.

\section{Research Result}

From the planning of the research method, the samples required for this research was 48 respondents. To anticipated unreturned and invalid questionnaire, 60 questionnaire was distributed to the respondent proportionally, and there were 54 questionnaire that was returned, 48 qualifying questionnaire was taken as planned, 4 questionnaire was considered invalid, that is 2 questionnaire was incomplete and 2 questionnaire was filled not seriously, where every question was answered with the same answer. The research was conducted approximately 10 months.

The data analysis in this research was conducted to the assessment data from the experts by using Fuzzy Analytic Hierarchy Process approach. The data obtained from the field was linguistic data, therefore to be able to conduct the weighting process by using fuzzy AHP method, the data previously have to be converted into triangular fuzzy number (TFN) form.

a. A Few factors besides defence and security factor apparently have a significant influence. This was shown with the weight of four factors besides from the defence and security factors such as ideological factors, political factors, economical factors, and social cultural factors that have reach 0.521 or more than $50 \%$ than the total weight.

\section{Research Limitation}

This research have some limitation such as:

a. The generalization of the decision making model of location determination of Naval Base, can only be conducted until the factor level. For the indicator level or operational level, an adjustment is required by identifying specific indicators to the issues that will be studied In order to used the model from this research.

b. Respondent from department elements was officials located in Jakarta, therefore ther were probability that the knowledge for the actual issues in the field especially remote areas that have become the perception source was inappropriate with the problems actually occurring.

\section{Conclusions}


From the analysis result and the discussion of the Location determination strategy of Naval Base model for each stakeholders to the combined model it was concluded that:

a. The location of military base was a non profit oriented public facility, which it existence will influence the strategic environment of Indonesian, therefore the decision in determining its location was a political decision of a nation. Generally, the factors considered in the political decision makings involved ideological, political, economical, social cultural factors, defence, and security (Dephan, 2007).

b. The assessment tendency with sectoral nature of the stakeholder was still found, that is the view point from the from sectoral interest perspective. It was visible from the higher weighting of factors related strongly with the main duty of their departments.

\section{REFERENCES}

Azkin, O and Guzin, O., 2007., Comparison Of Ahp And Fuzzy Ahp For The Multicriteria Decision Making Processes With Linguistic Evaluations., İstanbul Ticaret Üniversitesi Fen Bilimleri Dergisi Y11: 6 Say1:11Bahar 2007/1 s. 65-85

Buckley, J. 1985. Ranking Alternatives Using Fuzzy Members, Fuzzy Sets and Systems 15: 21-31

Chang, D.Y. 1996. Applications of the extent analysis method on fuzzy AHP, European Journal of Operational Research 95: 649-55

Chang, $\mathrm{Ru}$ Wu., et al. 2009. Applying fuzzy hierarchy multiple attributes to construct an expert decision making process. Expert Systems with Applications 36 (4): 7363-7368.

Deng, H., 1999, Multi-criteria analysis with fuzzy pair wise comparison, International Journal of Approximate Reasoning 21 (3): 215-231

Francis, R.L., White, J.A, 1992. Facility layout and location: an analytical approach. Prentice-Hall, Englewood Cliffs edisi 2

Kahraman, C. and Kulak, O. 2005. Fuzzy Multi-Criterion Selection Among Transportation Companies Using Axiomatic Design and Analytic Hierarchy Process. Information Sciences 170: 191-210.

Kahraman, C., D. Ruan, et al. 2003. Fuzzy group decision-making for facility location selection. Information Sciences 157: 135-153.

Kusumadewi, et. al, 2006. Fuzzy Multi Attribut Decision Making. Graha Ilmu Yogyakarta

Satty, T. L., 1980. The Analytical Hierarchy Process: Planning, Priority Setting, Resource Allocation. New York: McGraw-Hill

Saaty, T.L. 1993. The Analytical Hierarchy Process, McGrraw-Hill, New York. 1993.

Sekaran, U. 1992. Research Method for Business: A Skill-Building Approach, $2^{\text {nd }}$ ed., John Wiley \& Sons, New York.

Zadeh, L.A, 1975, The Concept of a Linguistic Variable and its Application to Approximate Reasoning-I, Information Sciences 8, 199-249 